\title{
Identification of naturalized goat breeds under conservation from northeastern Brazil using chromosomal markers
}

\author{
R.P. Santos ${ }^{1}$, P.R.A.M. Affonso ${ }^{1}$, D. Diniz ${ }^{1}$, A.S. Medrado ${ }^{2}$, K.M. Silva ${ }^{3}$ \\ and P.L.S. Carneiro ${ }^{1}$ \\ ${ }^{1}$ Departamento de Ciências Biológicas, \\ Universidade Estadual do Sudoeste da Bahia, Jequié, BA, Brasil \\ ${ }^{2}$ Universidade Estadual de Santa Cruz, Campus Soane Nazaré de Andrade, \\ Ilhéus, BA, Brasil \\ ${ }^{3}$ Empresa Brasileira de Pesquisa Agropecuária, Fazenda Três Lagoas, \\ Sobral, CE, Brasil \\ Corresponding author: P.R.A.M. Affonso \\ E-mail: paulomelloaffonso@yahoo.com.br
}

Genet. Mol. Res. 12 (3): 3193-3200 (2013)

Received September 3, 2012

Accepted November 26, 2012

Published August 29, 2013

DOI http://dx.doi.org/10.4238/2013.August.29.3

\begin{abstract}
In order to provide the first cytogenetic data of naturalized and threatened goat breeds from northeastern Brazil, cytogenetic analyses were carried out in individuals of Repartida and Moxotó breeds raised in Bahia and Ceará States. Males and females of both breeds had $2 n=60$, with 29 autosomal acrocentric pairs plus the sex chromosome pair. The number of nucleolar organizer region (NOR)-bearing chromosomes ranged from 6 to 8 per metaphase in Moxotó and Repartida goats, respectively. The active NORs in Repartida individuals were located exclusively at the terminal regions of the long arms, as usually detected in Bovidae. Otherwise, Moxotó specimens presented a large autosomal pair with NORs on short arms. GC-rich heterochromatin was detected at the centromeres in both breeds, although polymorphic terminal C-bands were visualized on pair 25 in Moxotó. In addition, GC-rich regions were detected at the
\end{abstract}


terminal regions of the long arms of a single pair in Repartida and of 20 chromosomes in Moxotó goats. The differences in both the number and/or position of Ag-NORs and GC-rich sites between Repartida and Moxotó breeds represent efficient cytogenetic markers that can be used in the identification and conservation of the genetic integrity of each lineage. In spite of the small effective population size of these breeds, chromosomal abnormalities related to drift or inbreeding effects were absent in the samples analyzed.

Key words: Chromosomal banding; Capra hircus; Karyotype; Ag-NORs

\section{INTRODUCTION}

Goats were first brought to Brazil by European colonizers approximately 500 years ago. Ever since, these populations have undergone intense adaptation as a result of natural selection under distinct climate conditions, such as the semi-arid and arid regions throughout northeastern Brazil (Egito et al., 2002; Mariante et al., 2011). Many herds accounted for the origin of naturalized or local breeds, which were used to represent the main genetic resources in regional goat farming (Quinzeiro Neto et al., 2011).

Over the last few decades, this activity has increased in Brazil, reaching up to an estimated number of 9.3 million individuals. From this total, nearly $91 \%$ are located in northeastern Brazil, representing an important income for local farmers (IBGE, 2010).

Despite their cultural and economic relevance to the arid and semi-arid regions, the naturalized goat breeds usually have low productivity levels in the absence of genetic improvement programs. Therefore, regional and traditional herds have been replaced by exotic breeds, mainly European industrial lineages of high performance driven by the selection of economically valuable traits (Taberlet et al., 2011). This behavior has eroded the unique genetic features of adapted indigenous lineages worldwide, eventually causing the extinction of naturalized breeds of small ruminants (Ma et al., 2006; Taberlet et al., 2011).

Repartida and Moxotó represent such threatened naturalized goat breeds in Brazil because of their small effective number and uncontrolled crossing with other genetic groups (Oliveira et al., 2005). A proper genetic characterization of such breeds is a critical step for the conservation of genetic resources, providing reliable information about effective size, inbreeding levels, and population structure, for instance. Thus, most authors agree that studies focusing on nuclear and mitochondrial DNA polymorphisms integrated with economical, social, and political parameters should be performed (Taberlet et al., 2011).

Conversely, cytogenetic studies in goats and other domestic animals might be useful for either the genetic characterization of breeds or the identification of chromosomal anomalies that might lead to infertility or subfertility (Basrur and Stranzinger, 2008; Ekambaram et al., 2011). Chromosomal analyses have been already used to diagnose the causes of reduced breeding performance in domesticated breeds, previously undetected by other genetic techniques (Nicodemo et al., 2008; El-Bayomi et al., 2011; Ticianelli et al., 2011) or to detect hybrid forms (Qu et al., 2012).

One of the first detailed cytogenetic studies in goats was provided by Henderson and Bruère (1979) who analyzed feral specimens derived from Saanen and Toggenburg 
breeds. Ever since, only a few cytogenetic reports have been published about goat breeds, e.g., Murciana-Granadina (Burguete, 1991) and Mahabubnagar (Ekambaram et al., 2011). Other studies are rather related to methodological or technical aspects (Mondal et al., 2007; Singh et al., 2011) or focused on chromosomal evolution in the family Bovidae (Di Meo et al., 2005; Schibler et al., 2009; Oh et al., 2011). Most reports describe conventional karyotype features, such as diploid number $(2 n)$ and chromosomal morphology, the identification of nucleolar organizer regions (NORs), and C- or G-banding patterns, although high-resolution cytogenetic techniques have already been developed (Di Meo et al., 2005; Schibler et al., 2009).

In the case of naturalized goat breeds from northeastern Brazil, no cytogenetic reports are available. Thus, the goal of this study was to characterize cytogenetically Repartida and Moxotó goats to identify possible cytogenetic markers for a detailed identification of lineages and/or chromosomal alterations related to inbreeding and small population size.

\section{MATERIAL AND METHODS}

Blood samples $(\sim 3 \mathrm{~mL})$ were collected from the jugular vein of 18 goats (4 males and 5 females of Repartida and 5 males and 4 females of Moxotó) raised in Jaquarari, Bahia (Empresa Baiana de Desenvolvimento Agrícola - EBDA), and Sobral, Ceará (Empresa Brasileira de Pesquisa Agropecuária - EMBRAPA). The blood was collected using Vacutainer ${ }^{\circledR}$ heparinized tubes, kept at a cool temperature $\left(\sim 4^{\circ} \mathrm{C}\right)$, and transported to a cytogenetics laboratory within $12 \mathrm{~h}$.

To obtain mitotic chromosomes, 15 to 18 blood drops were added to $5 \mathrm{~mL}$ sterile karyotype medium with RPMI (Cultilab ${ }^{\circledR}$ ) and stored at $37^{\circ} \mathrm{C}$ for $72 \mathrm{~h}$. Thirty minutes before this period ended, $250 \mu \mathrm{L} 0.05 \%$ colchicine was added. The following methodological steps were carried out according to Moorheard et al. (1960) using 20 min of hypotonic treatment $(0.075 \mathrm{M} \mathrm{KCl})$. A mean number of 20 metaphases were analyzed per individual and the best spreads were photographed using an Olympus BX51 photomicroscope for karyotyping according to Cribiu et al. (2001).

Heterochromatin was detected using a C-banding technique (Summer, 1972) and active NORs were visualized by silver nitrate staining (Howell and Black, 1980). Fluorochrome staining was performed to reveal GC- and AT-rich sites using chromomycin $\mathrm{A}_{3}\left(\mathrm{CMA}_{3}\right)$ and 4'-6-diamidino-2-phenylindole (DAPI), respectively (Schmid, 1980).

\section{RESULTS}

The modal diploid number of all sampled individuals was $2 \mathrm{n}=60$. The chromosomes were divided into 29 acrocentric autosomal pairs and the XX or XY sex chromosomes for females and males, respectively. The $\mathrm{X}$ chromosome was identified as the largest acrocentric element in the karyotype, while the $\mathrm{Y}$ chromosome was a small metacentric element (Figure 1).

Heterochromatin blocks (C-bands) were detected at the centromeric regions of nearly all autosomes and the X chromosome in both breeds analyzed (Figure 2). Nonetheless, the Moxotó breed was also characterized by a polymorphic C-band at the terminal region of pair 25, although this was only present in some individuals (Figure $2 \mathrm{c}$ and $\mathrm{d}$ ). 
a

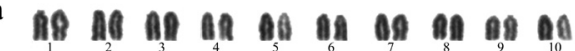

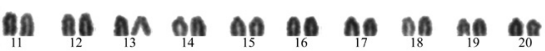

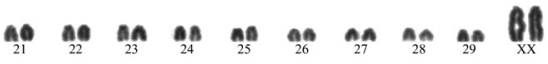

b

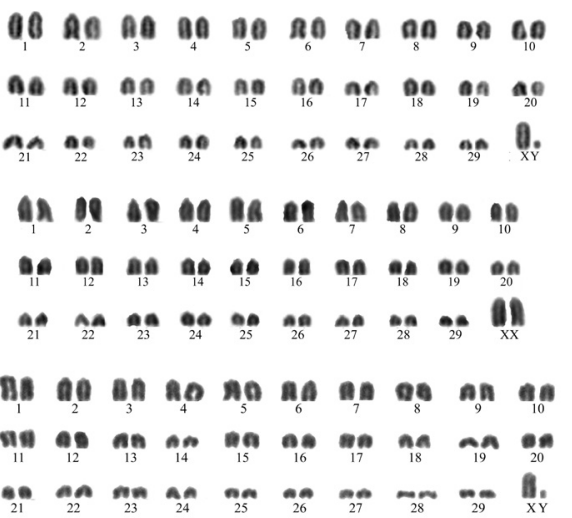

Figure 1. Karyotype of female $(\mathbf{a}, \mathbf{c})$ and male $(\mathbf{b}, \mathbf{d})$ individuals of Repartida $(\mathbf{a}, \mathbf{b})$ and Moxotó (c, d) goats.

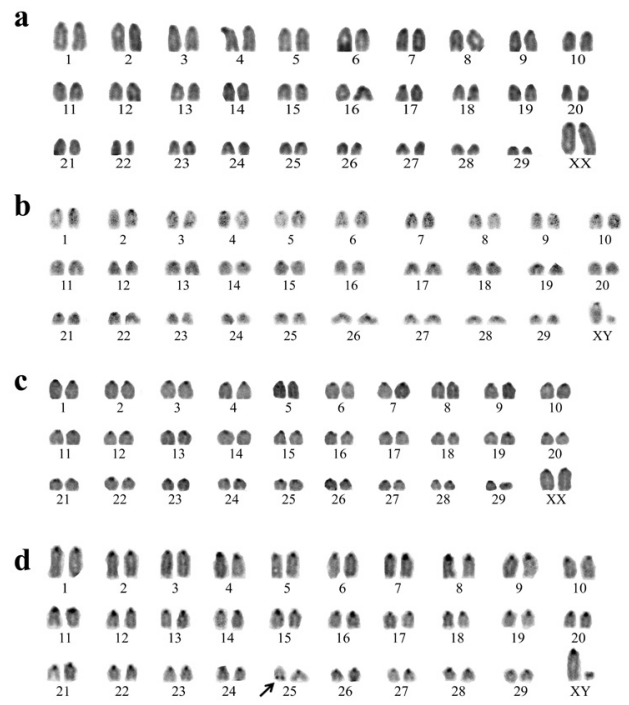

Figure 2. C-banded karyotypes of female (a, c) and male (b, d) individuals of Repartida (a, b) and Moxotó (c, d) goats. Note the polymorphic heterochromatin segment from the 25 th pair in a Moxotó male (indicated by the arrow).

Up to 8 and 6 NOR-bearing chromosomes per metaphase were visualized in Repartida and Moxotó goats, respectively (Figure 3). The active NORs in males and females of Repartida were restricted to the terminal regions of the long arms of 3 large acrocentric pairs and a small acrocentric pair (Figure 3a). In Moxotó, these regions comprised up to 5 chromosomal pairs. These included 2 homologous pairs and 2 non-homologous autosomes (a medium-sized 
and a small acrocentric chromosome), as well as on the short arms, close to the centromeres, of a large acrocentric pair. Furthermore, some NOR-bearing chromosomes in Moxotó and Repartida individuals were observed in association (Figure 3b).

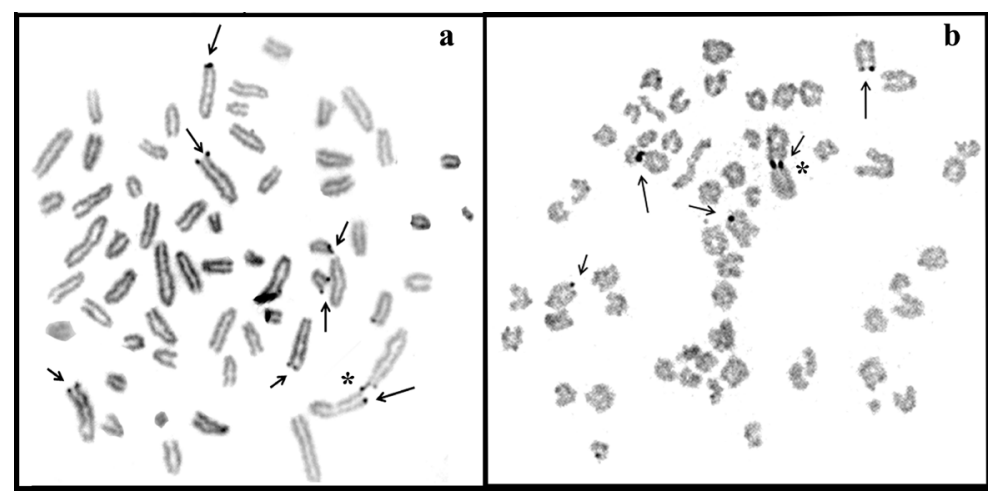

Figure 3. Somatic metaphases after silver nitrate staining showing active nucleolar organizer regions (NORs) in individuals of Repartida (a) and Moxoto (b) goats. The arrows indicate the NOR-bearing chromosomes in both breeds and the asterisks indicate the chromosomal associations by NORs.

Base-specific fluorochrome staining revealed GC-rich sites $\left(\mathrm{CMA}_{3}^{+}\right.$and DAPI $)$at the centromeres of all chromosomes in both goat breeds. However, several chromosomes bearing evident terminal $\mathrm{CMA}_{3}^{+} / \mathrm{DAPI}$ signals were also observed in Moxotó goats, while Repartida samples presented a subtle terminal GC-rich block in a single and small autosomal pair (Figure 4).
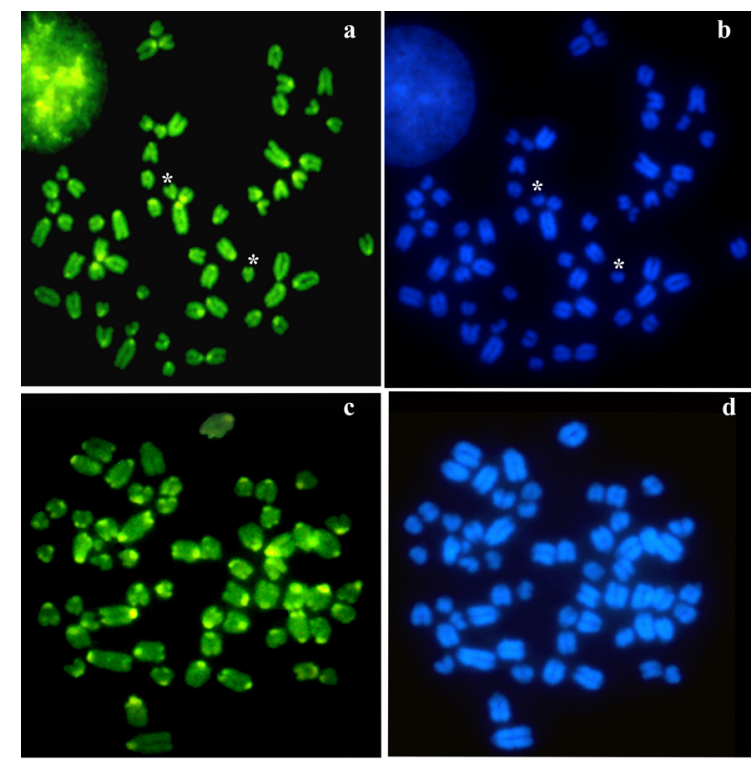

Figure 4. Somatic metaphase after $\mathrm{CMA}_{3}(\mathbf{a}, \mathbf{c})$ and DAPI $(\mathbf{b}, \mathbf{d})$ fluorochrome staining in Repartida $(\mathbf{a}, \mathbf{b})$ and Moxotó (c, d) goats. Note the high number of GC-rich blocks at terminal regions in Moxotó and a small terminal GC-rich region in a chromosomal pair in Repartida (indicated by the asterisks). 


\section{DISCUSSION}

Goats are among the 14 species that mostly contribute to human feeding worldwide. In 1983, the division of Genetic Resources and Biotechnology from EMBRAPA launched the National Program of Conversation of Animal Genetic Resources (Mariante et al., 2011). From that moment on, herds of the Repartida breed kept by the EBDA and the Moxoto breed raised at EMBRAPA-Caprinos were regarded as part of the germplasm bank within this initiative. At first, the only goal was to conserve their genetic material in situ for further utilization; however, in 1998, their genetic characterization was included to provide more detailed information about the conserved lineages. Therefore, molecular, cytogenetic, morphological (quantitative and qualitative traits), and pedigree analyses have been performed in these local breeds. In this sense, the cytogenetic characterization of Repartida and Moxoto breeds performed in the present study should be promoted once it provides the first chromosomal data in naturalized Brazilian goats.

Previous reports about cytogenetic traits in goats have been carried out to evaluate the incidence of chromosomal abnormalities. For instance, Robertsonian fusions were detected and associated with inbreeding and small population size in Murciana-Granadina (Burguete, 1991) and Angora breeds (Nicodemo et al., 2008). Actually, Robertsonian polymorphisms have been described frequently in inbred domestic or captive wild bovids (Graphodatsky et al., 2011; Pagacova et al., 2011).

Nonetheless, chromosomal abnormalities were absent in the cytogenetic analyses of both Brazilian goat breeds in spite of the reduced effective size of the studied populations and their susceptibility to inbreeding and genetic drift. Indeed, the karyotype macrostructure ( $2 \mathrm{n}$ and chromosomal morphology) of karyotyped individuals was highly conserved, being similar to the standard karyotype of Capra hircus (Cribiu et al., 2001; Di Meo et al., 2005; Singh et al., 2011).

Likewise, the C-banding pattern in both breeds analyzed was in agreement with that reported previously in goats and most ruminants (Oh et al., 2011). The only exception was the polymorphic terminal C-band in Moxotó; however, because of its sporadic presence, this heterochromatin segment in pair 25 cannot be considered a reliable chromosomal marker for this breed.

Conversely, Ag-NORs provided a distinct scenario. Active rDNA sites were firstly located in Saanen and Toggenburg goats, occupying the terminal regions of the long arms of pairs 2, 3, 4, 5, and 28. Indeed, terminal NORs seem to be a conserved feature in the family Bovidae, being also reported in sheep, cattle, buffalo, and aoudad (Henderson and Bruère, 1979; Di Berardino et al., 1981). In this study, the number of Ag-NORs was usually lower than in previous reports. Furthermore, Moxotó goats showed a reduced number of silver-stained rDNA clusters with an atypical location on the short arms of one pair, thereby placing them as a divergent lineage in relation to other breeds. In this sense, the application of fluorescent in situ hybridization with ribosomal probes might be useful to confirm if the positional and numerical differences in Ag-NORs are either related to differential transcription or structural variation.

Furthermore, chromosomal associations were often observed in Moxotó and, less frequently, in Repartida, mainly involving NOR-bearing chromosomes (Figures 3 and 4). Actually, a non-random chromosomal arrangement in metaphase spreads has been found frequently in goats (Andraszek et al., 2009) and other species with several acrocentric chromosomes, e.g., cattle and buffalo (Di Berardino et al., 1981). This event is thought to facilitate Robertsonian rearrangements, thus giving rise to bi-armed chromosomes (Aguilar et al., 1999; Grapho- 
datsky et al., 2011) like those observed in the differentiated karyotype of sheep $(2 \mathrm{n}=54)(\mathrm{Di}$ Meo et al., 2005).

Similar to Ag-NORs, fluorochrome staining was also informative to characterize the chromosomal structure of both naturalized Brazilian goat breeds. A remarkable difference in the number of terminal GC-rich sites was detected, since several chromosomes in Moxotó had $\mathrm{CMA}_{3}^{+}$signals at their telomeres (Figure 4). Even though this technique has been routinely applied to other vertebrates (Schmid, 1980; Bitencourt et al., 2012), little is known about the distribution of base-specific fluorochrome signals in mammals. As far as we are concerned, there are no reports available about combined $\mathrm{CMA}_{3}$ /DAPI staining in goat species, which restrains further considerations. Nonetheless, the GC-rich sites proved to be efficient markers to discriminate Moxotó and Repartida karyotypes and could be potentially used to understand heterochromatin composition in Bovidae.

Such cytogenetic differences detected in the Repartida and Moxotó breeds are relevant to the conservation of genetic resources in Brazilian goats. As previously commented, locally adapted goat breeds are threatened by unplanned or disorganized introgression with other exotic breeds (Oliveira et al., 2005; Ma et al., 2006; Taberlet et al., 2011). In Brazil, some institutions and local farmers have attempted to overcome this situation by maintaining genetic pools of naturalized breeds for further utilization in animal production (Mariante et al., 2011). Thus, the chromosomal markers obtained herein, particularly in the Moxotó breed, represent an additional characteristic for the identification of pure individuals when phenotypic classification is often imprecise, particularly in the lack of detailed pedigree data. Additional cytogenetic markers provided by other banding techniques might also be useful to determine the extension of chromosomal divergence between goat breeds.

Moreover, the apparent lack of chromosomal alterations in Moxotó and Repartida breeds is valuable information for conservation programs. It is well known that such abnormalities, particularly in heterozygosis, might have a negative effect on reproduction and fertility traits, determining economic losses or hindering conservation efforts (Robinson and Elder, 1993; Basrur and Stranzinger, 2008). However, it should be pointed out that the absence of chromosomal abnormalities in the specimens studied refer to a sample of only 2 breeds and a thorough cytogenetic analysis of all specimens should be practiced routinely in breeding management to avoid the abovementioned issues.

\section{ACKNOWLEDGMENTS}

The authors are grateful to Banco do Nordeste, Fundação de Amparo à Pesquisa do Estado da Bahia, Coordenação de Aperfeiçoamento de Pessoal de Nível Superior, Conselho Nacional de Desenvolvimento Científico e Tecnológico, EMBRAPA, EBDA, and Universidade Estadual do Sudoeste da Bahia for financial and/or logistic support for this study.

\section{REFERENCES}

Aguilar CT, Corrêa MMO and Galetti PM Jr (1998). Chromosome associations by centromeric heterochromatin in marine fishes. Chromosome Sci. 2: 73-76.

Andraszek K, Horoszewicz E and Smalec E (2009). Nucleolar organizer regions, satellite associations and nucleoli of goat cells (Capra hircus). Archiv. Tierzucht. 52: 177-186.

Basrur PK and Stranzinger G (2008). Veterinary cytogenetics: past and perspective. Cytogenet. Genome Res. 120: 11-25. 
Bitencourt JA, Affonso PR, Giuliano-Caetano L, Carneiro PL, et al. (2012). Population divergence and peculiar karyoevolutionary trends in the loricariid fish Hypostomus aff. unae from northeastern Brazil. Genet. Mol. Res. 11: 933-943.

Burguete I (1991). Cytogenetic study of the Spanish goat breed Murciana-Granadina. Genet. Sel. Evol. 23: S78-S80.

Cribiu EP, Di Berardino D, Di Meo GP, Eggen A, et al. (2001). International System for Chromosome Nomenclature of Domestic Bovids (ISCNDB 2000). Cytogenet. Cell Genet. 92: 283-299.

Di Berardino D, Iannuzzi L, Bettini TM and Matassino D (1981). Ag-NORs variation and banding homologies in two species of Bovidae: Bubalus bubalis and Bos taurus. Can. J. Genet. Cytol. 23: 89-99.

Di Meo GP, Perucatti A, Floriot S, Incarnato D, et al. (2005). Chromosome evolution and improved cytogenetic maps of the Y chromosome in cattle, zebu, river buffalo, sheep and goat. Chromosome Res. 13: 349-355.

Egito AA, Mariante AS and Albuquerque MSM (2002). Programa brasileiro de conservação de recursos genéticos animais. Arch. Zootec. 51: 39-52.

Ekambaram B, Gupta BR, Prakash MG, Sudhaker K, et al. (2011). Cytogenetic characterization of Mahabubnagar goats. Tamilnadu J. Vet. Anim. Sci. 7: 157-163.

El-Bayomi KM, El-Arab IE and Zaglool AW (2011). Cytogenetic analysis related to some infertility problems in cattle. Global Vet. 7: 323-329.

Graphodatsky AS, Trifonov VA and Stanyon R (2011). The genome diversity and karyotype evolution of mammals. Mol. Cytogenet. 4: 22.

Henderson LM and Bruère AN (1979). Conservation of nucleolus organizer regions during evolution in sheep, goat, cattle and aoudad. Can. J. Genet. Cytol. 21: 1-8.

Howell WM and Black DA (1980). Controlled silver-staining of nucleolus organizer regions with a protective colloidal developer: a 1-step method. Experientia 36: 1014-1015.

IBGE (Instituto Brasileiro de Geografia e Estatística) (2010). Produção da Pecuária Municipal. Available at [http://www. ibge.gov.br/home/]. Accessed January 19, 2012.

Ma Y-H, Rao S-Q, Lu S-J, Hou G-Y, et al. (2006). Phylogeography and origin of sheep breeds in Northern China. Conserv. Genet. 7: 117-127.

Mariante AS, Albuquerque MSM and Ramos AF (2011). Criopreservação de recursos genéticos animais brasileiros. Rev. Bras. Prod. Anim. 35: 64-68.

Mondal NK and Chakrabarti S (2007). A simpler, cheaper and quicker method to study somatic chromosomes from goat, Capra hircus (L.). Cytologia 72: 419-425.

Moorhead PS, Nowell PC, Mellman WJ, Battips DM, et al. (1960). Chromosome preparations of leukocytes cultured from human peripheral blood. Exp. Cell Res. 20: 613-616.

Nicodemo D, Pauciullo A, Castello A, Soysal I, et al. (2008). A cytogenetic study on the Angora breed of goat (Capra hircus) reared in Turkey. J. Tek. Agric. Fac. 5: 247-252.

Oh SH, Yun YM, Lee JE, Kim IY, et al. (2011). G-, R- and C-band patterns of goral (Nemorhaedus caudatus) and comparison to goat (Capra hircus). Mol. Cells 31: 351-354.

Oliveira RR, Egito AA, Ribeiro MN, Paiva SR, et al. (2005). Genetic characterization of the Moxotó goat breed using RAPD markers. Pesq. Agropec. Bras. 40: 233-239.

Pagacova E, Cernohorska H, Kubickova S, Vahala J, et al. (2011). Centric fusion polymorphism in captive animals of family Bovidae. Conserv. Genet. 12: 71-77.

Qu KX, He ZX, Nie WH, Zhang JC, et al. (2012). Karyotype analysis of mithun (Bos frontalis) and mithun bull x Brahman cow hybrids. Genet. Mol. Res. 11: 131-140.

Quinzeiro Neto T, Lana AMQ, Reis GL, Holanda EV Jr, et al. (2011). Caracterização da caprino-ovinocultura de corte de produtores de Jussara e Valente, BA. Rev. Caatinga 24: 165-173.

Robinson TJ and Elder FFB (1993). Cytogenetics: Its role in wildlife management and the genetic conservation of mammals. Biol. Conserv. 63: 47-51.

Schibler L, Di Meo GP, Cribiu EP and Iannuzzi L (2009). Molecular cytogenetics and comparative mapping in goats (Capra hircus, $2 \mathrm{n}=60$ ). Cytogenet. Genome Res. 126: 77-85.

Schmid M (1980). Chromosome banding in amphibia. IV. Differentiation of GC- and AT-rich chromosome regions in Anura. Chromosoma 77: 83-103.

Singh M, Sharma AK and Yadav P (2011). Characterization of GSF289: a fibroblast cell line derived from goat ear skin explants. J. Biotechnol. Res. 3: 1-6.

Sumner AT (1972). A simple technique for demonstrating centromeric heterochromatin. Exp. Cell Res. 75: 304-306.

Taberlet P, Coissac E, Pansu J and Pompanon F (2011). Conservation genetics of cattle, sheep, and goats. C R Biol. 334: 247-254.

Ticianelli JS, Oliveira BMM, Zogno MA, Arruda RP, et al. (2011). Intersexo e outras anomalias do desenvolvimento do aparelho reprodutor nos animais domésticos e o auxílio da citogenética para o diagnóstico. Rev. Bras. Reprod. Anim. 35: $26-32$. 